\title{
MESHLESS APPROACH AS AN ALTERNATIVE TO FINITE ELEMENT METHOD IN SOLID MECHANICS NUMERICAL MODELING
}

\author{
Jurica Sorić, Boris Jalušić, Tomislav Jarak
}

\begin{abstract}
Summary
Meshless approaches enable discretizations of a computational model only by a set of nodes, which do not need to be connected to elements. This paper presents the meshless local Petrov-Galerkin method, which belongs to truly meshless approaches, as it does not require any kind of mesh or background cells for either interpolation or integration. Full displacement and mixed formulations are presented. The full displacement approach is used for the solution of a three-dimensional elasto-static problem, while the mixed approach is applied for the modeling of deformation responses of shell-like structures. The modeling of material discontinuities is performed by the mixed meshless local Petrov-Galerkin approach by employing the collocation method. The efficiency and accuracy of all the presented methods are tested and compared with finite element formulations in numerical examples. It is demonstrated that the meshless approaches may be considered an alternative to the well-known finite element method regarding certain problems.
\end{abstract}

Keywords: meshless method; local Petrov-Galerkin formulation; mixed meshless approach; collocation meshless approach.

\section{INTRODUCTION}

In the recent years, meshless approaches have been proposed as an alternative to the well-known finite element method. These relatively new computational strategies have attracted considerable attention due to their capability to solve a boundary value problem without a meshing procedure. In contrast to the finite element formulation, computational model may be discretized only by nodes, which do not need to be connected to elements. Thus, the nodes can be easily added and removed without burdensome remeshing of 
the entire structure. Furthermore, some issues associated with the mesh-based finite element method (FEM), such as a time-consuming mesh generation or element distortion problems, may be efficiently overcome by using meshless formulations. On the other hand, the derivation of interpolation functions in the meshless formulations is more complex than in the finite element approach.

Nowadays, there are a large number of meshless methods as a result of intense development over the last two decades. They can be divided into three basic groups according to the manner of obtaining and solving the discretized system of equations: the strong form; the weak form; and the weak-strong form methods.

The strong form approaches are based on the strong form of differential equations and are usually referred to as collocation methods. Herein, the governing equations are written and imposed in discretization nodes of the numerical model, and accordingly, there is no numerical integration. Some of the representatives of these methods are the Finite difference method [1]; and the Radial basis collocation method [2,3]. Although the strong form methods possess several attractive characteristics, e.g. a simple algorithm for assembling a solvable system of equations, speed and computational efficiency, they may have some numerical stability problems that can lead to inaccuracies.

In the weak form methods, the partial differential equations with the accompanied natural boundary conditions are expressed in an integral form using different numerical approaches. The weak forms are then used to obtain the system of algebraic equations through the numerical integration procedure, using predetermined background cells that can be defined globally - over the entire problem domain [4] or locally - over a part of the computational domain [5]. The operation of integration smudges the error within the integrated area; this increases the accuracy and stability of solutions. Integration acts as a kind of regularization to stabilize the numerical solution.

The meshless global weak form methods are based on the integration of the global Galerkin weighted residual equations and the use of meshless approximations functions. The background cells are required over the entire computational domain for the purpose of the integration. The Element Free Galerkin (EFG) [4] and the Reproducing Kernel Particle Method (RKPM) [6] can be mentioned as representatives of the global weak form methods. The meshless local weak form methods are based on the integration of the so-called local weak forms of Galerkin equations. Herein, local integration areas are often very simple - e.g. spherical, circular, or rectangular in shape. They may mutually overlap, and are automatically built during the calculation process. Some of the representatives of these methods are the HP-Cloud method [7] and the Meshless Local Petrov-Galerkin (MLPG) method [8]. Numerical integration makes the weak form methods computationally more expensive than the collocation methods. 
The weak-strong form methods have been designed to utilize the advantages of the weak and strong methods, and to avoid their disadvantages $[9,10]$. They have been created for the purpose of removing the need for background integration cells as much as possible, and at the same time to provide stable and accurate solutions, even for problems in which the derivative boundary conditions are present. The main idea of this type of methods is to create a system of discretized equations, where weak and strong methods are used selectively, depending on the placement of the discretization nodes. The weak form methods are mostly used at the nodes where the derivative boundary conditions (natural boundary conditions) are prescribed. The strong form methods are utilized in all the remaining nodes of the computational model.

In this contribution, the MLPG method is applied to solve various physical problems. In 3-D elasticity, the Boussinesq problem involving concentrated load acting on a semi-infinite elastic medium is solved [11]. The mixed MLPG method developed in [12] for the analysis of shell-like structures is presented next. Thereby, undesired thickness and shear locking phenomena are eliminated in an efficient way. In addition, the mixed MLPG method employing the collocation approach [13] is used for the modeling of material discontinuity in two-dimensional heterogeneous structures. All the meshless approaches considered demonstrate superiority in comparison with the standard finite element formulation in terms of accuracy and convergence rates.

\section{MESHLESS FORMULATION FOR THREE-DIMENSIONAL ELASTICITY}

According to the three-dimensional solid concept, the equilibrium equations in a domain of the volume $\Omega$, which is bounded by the surface $\Gamma$, are given by

$$
\sigma_{i j, j}+b_{i}=0, \text { in } \Omega,
$$

where $\sigma_{i j}$ are the stress tensor components and $b_{i}$ denotes the body forces. The indices $i$, $j$, which take the values $1,2,3$, refer to the Cartesian coordinates $x, y, z$. On the boundary $\Gamma$, the following boundary conditions are assumed:

$$
\begin{gathered}
u_{i}=\bar{u}_{i}, \text { on } \Gamma_{u}, \\
t_{i}=\sigma_{i j} n_{j}=\bar{t}_{i,} \text { on } \Gamma_{t},
\end{gathered}
$$

where $u_{i}$ are the displacement components and $t_{i}$ stands for the surface traction components. $\Gamma_{u}$ and $\Gamma_{t}$ are parts of the global boundary with prescribed displacements $\bar{u}_{i}$ and tractions $\bar{t}_{i}$, respectively. $n_{j}$ denotes direction cosines of the outward normal on the boundary $\Gamma$ of the volume $\Omega$. 
In the MLPG method, the equilibrium equations may be written in a weak form over a local sub-domain $\Omega^{I}$ defined around a grid node $I$, which may be expressed in the following form:

$$
\int_{\Omega_{s}^{I}}\left(\sigma_{i j, j}+b_{i}\right) v_{i} \mathrm{~d} \Omega-\alpha \int_{\Gamma_{s u}^{I}}\left(u_{i}-\bar{u}_{i}\right) v_{i} \mathrm{~d} \Gamma=0 .
$$

Herein, $u_{i}$ is the trial function describing the displacement field, while $v_{i}$ is the test function. In the MLPG method applied, the test and trial functions may be chosen from different functional spaces. The local sub-domain $\Omega^{I}$ is a small region inside the domain $\Omega$ and could be of any geometric shape and size, Fig. 1. Here in the 3D analysis, the local sub-domains are taken to be of spherical shape. The local sub-domains may overlap, and they cover the whole global domain $\Omega . \Gamma^{I}{ }_{s u}$ is a part of the boundary $\partial \Omega^{I}{ }_{s}$ of the local sub-domain with the prescribed displacement $\bar{u}_{i}$, and $\alpha$ denotes a penalty parameter, $\alpha>>1$, which is introduced in order to satisfy the geometric boundary conditions.

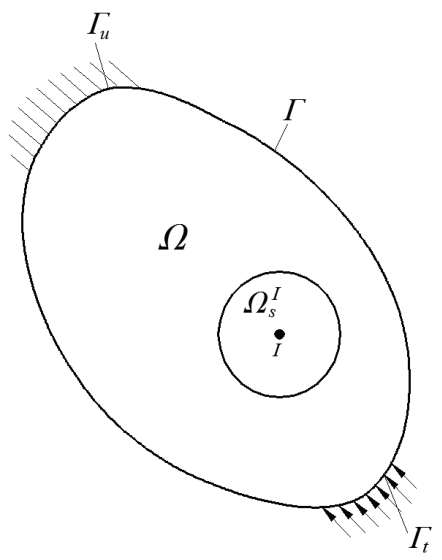

Fig. 1. Definition of local sub-domain

Sl. 1. Određivanje lokalnog potpodručja

Using the divergence theorem and some mathematical manipulation according to [11], the local symmetric weak form (LSWF) for linear elasticity may be expressed as:

$$
\int_{\Omega_{s}^{I}} \sigma_{i j} v_{i, j} \mathrm{~d} \Omega-\int_{L_{s}^{I}} t_{i} v_{i} \mathrm{~d} \Gamma-\int_{\Gamma_{s u}^{I}} t_{i} v_{i} \mathrm{~d} \Gamma+\alpha \int_{\Gamma_{s u}^{I}} u_{i} v_{i} \mathrm{~d} \Gamma=\int_{\Gamma_{s u}^{I}} \bar{t}_{j} v_{i} \mathrm{~d} \Gamma+\alpha \int_{\Gamma_{s u}^{I}} \bar{u}_{i} v_{i} \mathrm{~d} \Gamma+\int_{\Omega_{s}^{I}} b_{i} v_{i} \mathrm{~d} \Omega .
$$

Herein, $L_{s}^{I}$ is the part of the local boundary $\partial \Omega^{I}{ }_{s}$ that is totally inside the global domain, $\Gamma_{s t}^{I}$ is the part of $\partial \Omega^{I}{ }_{s}$ that coincides with the global traction boundary, i.e., $\Gamma_{s t}^{I}=\partial \Omega_{s}^{I} \cap \Gamma_{t}$, and $L_{s u}^{I}$ is the part of $\square \Omega^{I}{ }_{s}$ that coincides with the global geometric boun- 
dary, i.e., $\Gamma_{s t}^{I}=\partial \Omega^{I}{ }_{s} \cap \Gamma_{u}$. If the Heaviside step function is chosen as the test function in each local sub-domain, defined as

$$
v(x)=\left\{\begin{array}{ll}
1 & \text { at } x \in \Omega_{s} \\
0 & \text { at } x \notin \Omega_{s}
\end{array},\right.
$$

the LSWF (4) may be simplified as

$$
-\int_{L_{s}^{I}} t_{i} \mathrm{~d} \Gamma-\int_{\Gamma_{s u}^{I}} t_{\mathrm{i}} \mathrm{d} \Gamma+\alpha \int_{\Gamma_{s u}^{I}} u_{i} \mathrm{~d} \Gamma=\int_{\Gamma_{s t}^{I}} \bar{t}_{j} \mathrm{~d} \Gamma+\alpha \int_{\Gamma_{s t}^{I}} \bar{u}_{i} \mathrm{~d} \Gamma+\int_{\Omega_{s}^{I}} b_{i} \mathrm{~d} \Omega .
$$

As evident from equation (6), there is no domain integration involved in the lefthand side. Under the assumption of zero body force, the domain integration is totally eliminated.

The trial function is chosen to be the moving least square (MLS) approximation [14], defined over a number of nodes within the domain of influence. While the local sub-domain $\Omega^{I}{ }_{s}$ is defined as the region over which the integration around node $I$ is carried out, and in this text, it is set to be equal to the support of the nodal test function, the domain of influence is defined as the region that includes all the nodes whose MLS nodal trial shape functions do not vanish in the local sub-domain of the current node $I$. In other words, the domain of influence contains all the nodes that have a non-zero coupling in the stiffness matrix with the current node $I$ as shown in Fig. 2.

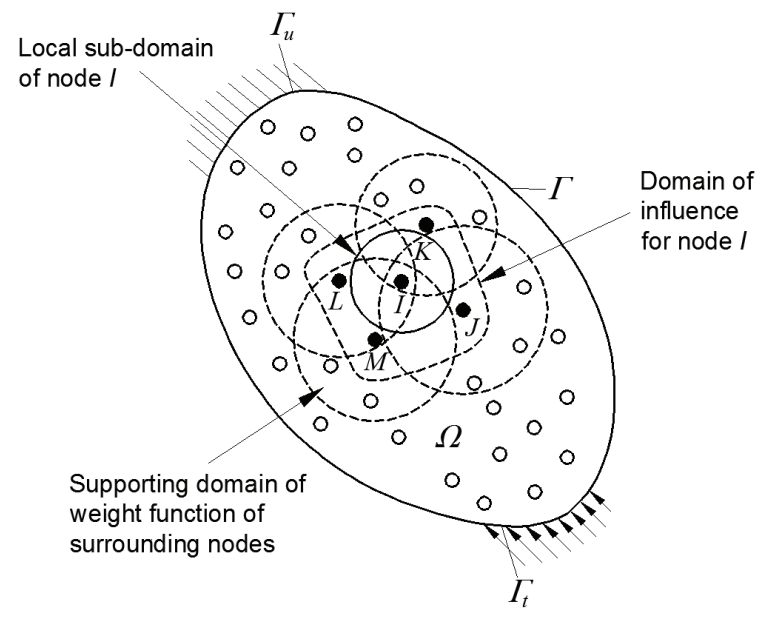

Fig. 2. MLPG trial and test domain

SI. 2. Interpolacijsko i testno područje u MLPG (bezmrežnoj lokalnoj Petrov-Galerkinovoj) formulaciji 
In Fig. 2, the solid-lined sphere surrounding the node $I$ represents the local subdomain, where integration is carried out. The dashed spheres surrounding the nodes $J$, $K, L, M \ldots$ represent the supporting domains of the MLS weight functions of the nodes whose weight functions do not vanish in the local sub-domain of the node $I$. The volume surrounded by the dashed curve represents the domain of influence of the node $I$.

The MLS method is generally considered to be one of useful interpolation schemes that approximate random data with reasonable accuracy. The characteristics of the MLS have been widely discussed in literature $[15,16]$. Accordingly, the displacement distribution in three-dimensional space may be expressed as

$$
\mathbf{u}=\sum_{J=1}^{N} \phi_{J}(x, y, z) \hat{\mathbf{v}}_{J},
$$

where

$$
\begin{aligned}
& \mathbf{u}^{T}=\left[\begin{array}{lll}
u & v & w
\end{array}\right], \\
& \hat{\mathbf{v}}_{J}^{T}=\left[\begin{array}{lll}
\hat{u} & \hat{v} & \hat{w}
\end{array}\right]_{J},
\end{aligned}
$$

$\hat{\mathbf{v}}_{J}$ is the vector with the fictitious nodal displacement components, and $\mathrm{N}$ is the total number of nodes. In relation (7), $\phi_{J}(x, y, z)$ stands for the shape function of the MLS approximation associated with the node $J$. It should be stressed that in the general case, the MLS approximation function does not interpolate the nodal values, and therefore, they are called fictitious values. In other words, it does not possess the Kronecker delta property. This is the reason why the penalty parameter is introduced in (3) in order to impose the displacement boundary condition. Using the derivation procedure described in [11] and [17], the nodal shape function is obtained in the following form:

$$
\phi_{J}(\mathbf{x})=\sum_{i=1}^{m} p_{i}(\mathbf{x})\left[\mathbf{A}^{-1}(\mathbf{x}) \mathbf{B}(\mathbf{x})\right]_{i J}
$$

with the matrices $\mathbf{A}(\mathbf{x})$ and $\mathbf{B}(\mathbf{x})$ defined as

$$
\begin{gathered}
\mathbf{A}(\mathbf{x})=\sum_{J=1}^{N} W_{J}(\mathbf{x}) \mathbf{p}\left(\mathbf{x}_{J}\right) \mathbf{p}^{T}\left(\mathbf{x}_{J}\right) \\
\mathbf{B}(\mathbf{x})=\left[\begin{array}{llllll}
W_{1}(\mathbf{x}) \mathbf{p}\left(\mathbf{x}_{1}\right) & W_{2}(\mathbf{x}) \mathbf{p}\left(\mathbf{x}_{2}\right) & \ldots & W_{J}(\mathbf{x}) \mathbf{p}\left(\mathbf{x}_{J}\right) & \ldots & W_{N}(\mathbf{x}) \mathbf{p}\left(\mathbf{x}_{N}\right)
\end{array}\right] .
\end{gathered}
$$

In the above relations, $W_{J}(\mathbf{x})$ is the weight function associated with the node $J$, and $\mathbf{p}(\mathbf{x})$ denotes a vector comprising a complete monomial basis of order $m, \mathbf{p}^{T}(\mathbf{x})=\left[p_{1}(\mathbf{x})\right.$ $\left.p_{2}(\mathbf{x}) \quad \ldots \quad p_{i}(\mathbf{x}) \quad \ldots \quad p_{m}(\mathbf{x})\right] . \mathbf{x}$ is the vector which contains coordinates, $\mathbf{x}^{T}=\left[\begin{array}{lll}x & y & z\end{array}\right]$. The 
linear basis is expressed as

$$
\mathbf{p}^{T}(\mathbf{x})=\left[\begin{array}{llll}
1 & x & y & z
\end{array}\right]
$$

and the quadratic basis is

$$
\mathbf{p}^{T}(\mathbf{x})=\left[\begin{array}{llllllllll}
1 & x & y & z & x^{2} & y^{2} & z^{2} & x y & y z & z x
\end{array}\right] .
$$

In this text, the $4^{\text {th }}$ order spline type weight function [17] is assumed

$$
W_{J}(\mathbf{x})= \begin{cases}1-6\left(\frac{d_{J}}{r_{J}}\right)^{2}+8\left(\frac{d_{J}}{r_{J}}\right)^{3}-3\left(\frac{d_{J}}{r_{J}}\right)^{4} & 0 \leq d_{J} \leq r_{J} . \\ 0 & d_{J}>r_{J}\end{cases}
$$

By substituting the MLS interpolation function (7) into the formulation (6), the following discretized system of linear equations is obtained:

$$
\sum_{J=1}^{N}\left[\int_{L_{s}} \mathbf{N D B}_{J} \mathrm{~d} \Gamma+\int_{\Gamma_{s t}} \mathbf{S N D B} \mathbf{B}_{J} \mathrm{~d} \Gamma-\alpha \int_{\Gamma_{s u}} \mathbf{S} \boldsymbol{\Phi}_{J} \mathrm{~d} \Gamma\right] \mathbf{v}_{J}=-\int_{\Gamma_{s t}} \overline{\mathbf{t}} \mathrm{d} \Gamma-\int_{\Omega_{s}} \mathbf{b} \mathrm{d} \Omega-\alpha \int_{\Gamma_{s u}} \overline{\mathbf{u}} \mathrm{d} \Gamma
$$

where, in the three-dimensional space,

$$
\begin{aligned}
& \mathbf{N}=\left[\begin{array}{cccccc}
n_{1} & 0 & 0 & n_{2} & 0 & n_{3} \\
0 & n_{2} & 0 & n_{1} & n_{3} & 0 \\
0 & 0 & n_{3} & 0 & n_{2} & n_{1}
\end{array}\right], \mathbf{B}_{J}=\left[\begin{array}{ccc}
\phi_{J, 1} & 0 & 0 \\
0 & \phi_{J, 2} & 0 \\
0 & 0 & \phi_{J, 3} \\
\phi_{J, 2} & \phi_{J, 1} & 0 \\
0 & \phi_{J, 3} & \phi_{J, 2} \\
\phi_{J, 3} & 0 & \phi_{J, 1}
\end{array}\right], \boldsymbol{\Phi}_{J}=\left[\begin{array}{ccc}
\phi_{J} & 0 & 0 \\
0 & \phi_{J} & 0 \\
0 & 0 & \phi_{J}
\end{array}\right], \\
& \mathbf{S}=\left[\begin{array}{ccc}
S_{1} & 0 & 0 \\
0 & S_{2} & 0 \\
0 & 0 & \mathrm{~S}_{3}
\end{array}\right] \quad \text { with } S_{i}=\left\{\begin{array}{l}
1 \text { if } u_{i} \text { is prescribed on } \Gamma_{u} \\
0 \text { if } u_{i} \text { is not prescribed on } \Gamma_{u}, i=1,3,
\end{array}\right.
\end{aligned}
$$

and $\mathbf{D}$ stands for the standard three-dimensional elasticity matrix. Using the standard well-known numerical procedures, the global set of equations is derived, which is as usually expressed in the following matrix form

$$
\mathbf{K V}=\mathbf{F} \text {, }
$$

where $\mathbf{K}$ is the stiffness matrix, $\mathbf{V}$ is the vector of nodal displacements, and $\mathbf{F}$ stands for the prescribed loading. 


\section{Three-Dimensional Boussinesq Problem}

The Boussinesq problem is a classical problem for the study of contact, penetration, and impact problems. The problem can be simply described as concentrated load acting on a semi-infinite elastic medium with no body force. Because of the strong singularity in the Boussinesq problem, it is very difficult to get an accurate result using domain discretization methodology such as the finite element method. The exact displacement field within the semi-infinite medium is given by [18].

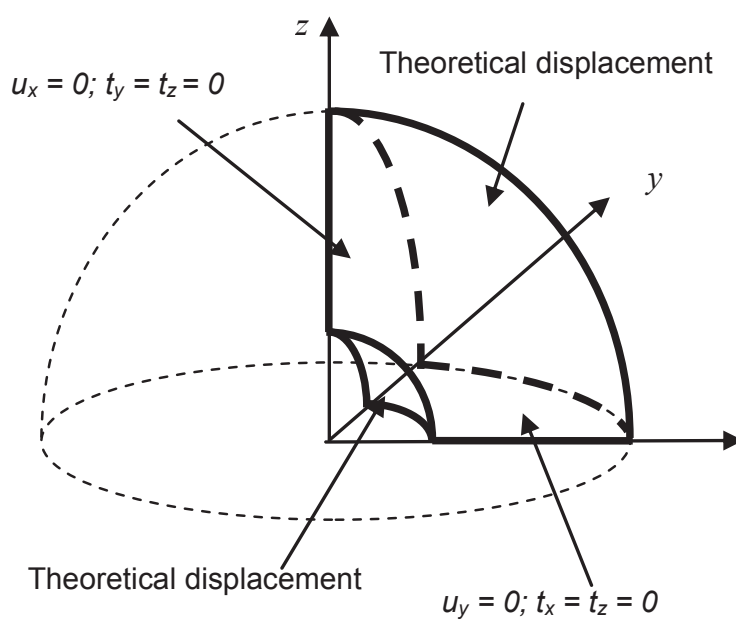

Fig. 3. Simulation model for Boussinesq Problem

SI. 3. Simulacijski model za Boussinesqov problem

A one-eighth of a sphere is used to simulate the semi-infinite continuum. In order to avoid direct encounter with the singular loading point, the theoretical displacement is applied on a small spherical surface with the radius as low as $2.5 \%$ of the total radius of the sphere. The symmetric boundary conditions are applied on the surfaces of the one-eighth sphere, Fig. 3. An isotropic material of $E=1,000$ and $v=0.25$ is used in the simulation. The 1,177-node MLPG model and 1,159 node FEM model are shown in Figs. 4 and 5. 


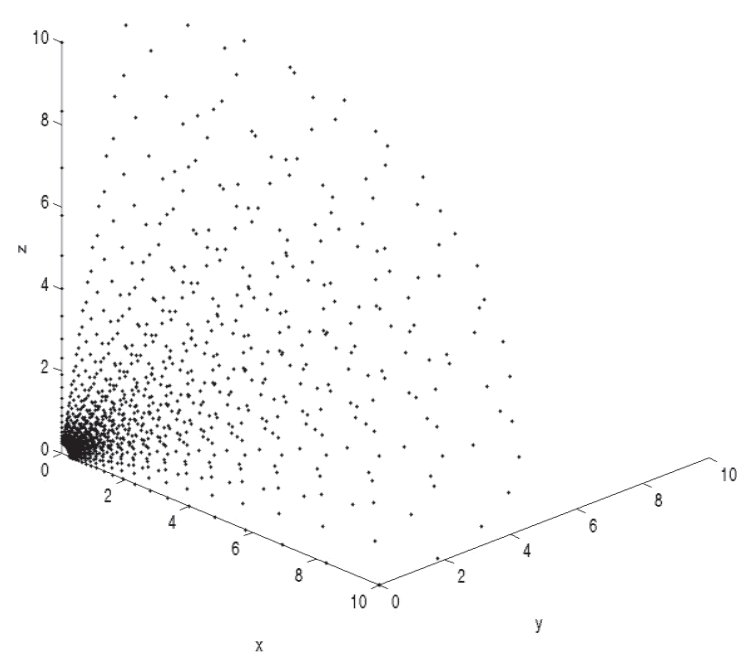

Fig. 4. MLPG model with 1,177 Nodes for Boussinesq problem [11]

Sl. 4. MLPG model s 1177 čvorova za Boussinesqov problem [11]

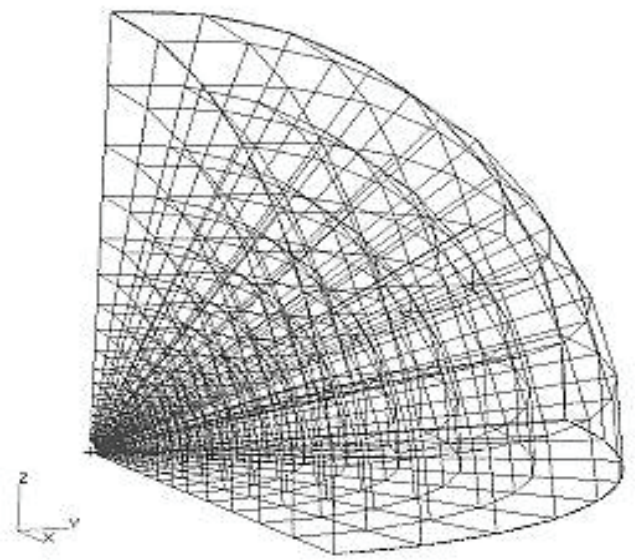

Fig. 5. FEM model with 1,159 nodes for Boussinesq problem [11]

Sl. 5. Model metode konačnih elemenata s 1159 čvorova za Boussinesqov problem [11]

The two models have similar nodal distances at the stress-concentrated area. However, it can be seen that a lot more nodes need to be added in the FEM model in order to prevent element distortion and maintain a reasonable element aspect ratio. In Fig. 6, the 
relative errors of von Mises stress and strain energy for both the MLPG and the FEM method are plotted. It can be seen that even with a node number as high as 11,112 , the accuracy of the finite element method is still far less than the MLPG method.

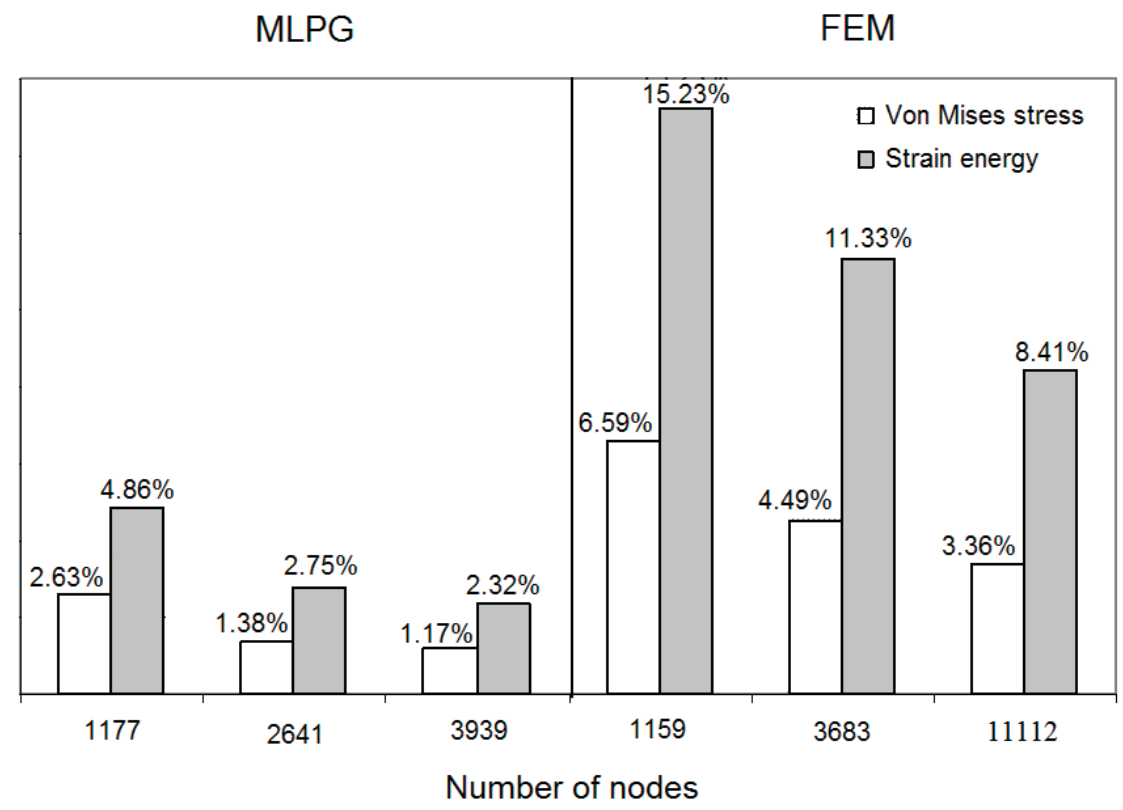

Fig. 6. Von Mises and strain energy relative error vs. node number [11]

SI. 6. Relativne greške za von Misesovo naprezanje i energiju deformiranja u odnosu na broj čvorova [11]

\section{MIXED MLPG METHOD FOR THE ANALYSIS OF SHELL-LIKE STRUCTURES}

An efficient mixed meshless formulation based on the Local Petrov-Galerkin approach described above has been developed for the analysis of shell-like structures. The 3-D solid-shell concept used in the finite element formulations [19] and [20] is adopted, and the shell geometry, which can be described exactly, is analyzed. Plate structures may be considered a special case of the shell geometry defined by the zero value of the Gaussian curvature. Discretization is performed by the nodes located on the upper and lower surfaces, and the local weak form of the equilibrium over the prismatic local 
sub-domain, surrounding the couple of nodes positioned on the opposite surfaces, is derived. Certain strain and stress components are first approximated independently, but their nodal values are eliminated from the discretized equation system locally, yielding a global system of equations with only nodal displacements as unknowns [12]. This is achieved by enforcing the kinematic relations between approximated strains and displacements at the nodes by means of a collocation approach. Instead of the standard MLS interpolation functions, a new modified MLS shape function, proposed in [21] and [22], obeying the interpolation condition with high accuracy, is implemented. Thus, a penalty approach for imposing the essential boundary conditions is avoided. Furthermore, the thickness and shear locking phenomena are fully suppressed due to the employed mixed numerical strategy.

According to the formulation presented in [12], the shell structure is described by the curvilinear coordinates $\theta^{k}, \mathrm{k}=1,2,3$, defined into the global Cartesian space, and then mapped into a parametric space, where the curved middle surface is transformed into the two-dimensional unit square in the $\zeta^{1}, \zeta^{2}$ - parametric plane. $\zeta^{1}$ and $\zeta^{2}$ are the normalized parametric coordinates defined as $\zeta^{\alpha}=\frac{\theta^{\alpha}}{\theta^{\alpha}{ }_{\max }}$, and thus their range is $0 \leq \zeta^{\alpha} \leq 1$ as shown in Fig. 7. Herein, $\theta^{\alpha}$ denotes the middle surface convective coordinates, and $\theta^{3}$ is the local coordinate in the thickness direction. The nodes are uniformly generated on the upper and lower surfaces in the parametric space, and then mapped into the global Cartesian coordinates. The prismatic local sub-domains are defined in the parametric space around each couple of nodes positioned on the opposite discretized surfaces. All interpolations are performed by using the parametric coordinates $\zeta^{i}$.

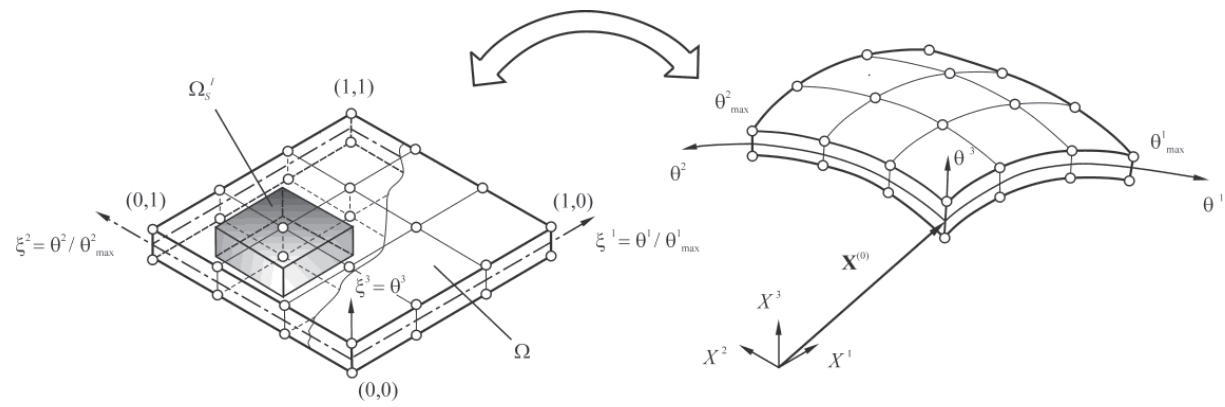

Fig. 7. Parametric representation and discretization of shell geometry

SI. 7. Parametarski prikaz i diskretizacija ljuskaste geometrije 
The derivation of the governing equation is based on the 3D meshless formulation presented in the previous section. Instead of the standard 3D discretization, here the nodes are distributed over the opposite surface, forming shell-like structures with arbitrary thickness as shown in Fig. 7. Accordingly, the test function is approximated over the thickness, and here the linear distribution is assumed as

$$
v\left(\xi^{j}\right)=c_{0}+c_{1}\left(\xi^{3}\right)
$$

with $c_{0}$ and $c_{1}$ as arbitrarily chosen real constants. Using the procedure described in the previous section, the governing equations for the local sub-domain $\Omega^{I}$ are derived in the following form:

$$
\begin{gathered}
-\int_{L_{s}^{I}} n_{j} \sigma_{i j} \mathrm{~d} \Gamma-\int_{\Gamma_{s u}^{I}} n_{j} \sigma_{i j} \mathrm{~d} \Gamma=\int_{\Omega_{s}^{I}} b_{i} \mathrm{~d} \Omega+\int_{\Gamma_{s t}^{I}} \overline{t_{i}} \mathrm{~d} \Gamma, \\
\int_{\Omega_{s}^{I}} \xi^{3},{ }_{j} \sigma_{i j} \mathrm{~d} \Omega-\int_{L_{s}^{I}} \xi^{3} n_{j} \sigma_{i j} \mathrm{~d} \Gamma-\int_{\Gamma_{s u}^{I}} \xi^{3} n_{j} \sigma_{i j} \mathrm{~d} \Gamma=\int_{\Omega_{s}^{I}} \xi^{3} b_{i} \mathrm{~d} \Omega+\int_{\Gamma_{s t}^{I}} \xi^{3} \overline{t_{i}} \mathrm{~d} \Gamma .
\end{gathered}
$$

Here, all tensor and vector components are defined in the Cartesian coordinates, i.e. $\boldsymbol{\sigma}=\sigma_{i j} \mathbf{e}_{i} \otimes \mathbf{e}_{j}, \mathbf{t}=t_{i} \mathbf{e}_{i}, \mathbf{n}=n_{i} e_{i}$. However, the integration over the local sub-domain is performed in the parametric coordinates, where the volume element is expressed as

$$
\mathrm{d} \Omega=\left(\overline{\mathbf{G}}_{1} \times \overline{\mathbf{G}}_{2}\right) \cdot \overline{\mathbf{G}}_{3} \mathrm{~d} \xi^{1} \mathrm{~d} \xi^{2} \mathrm{~d} \xi^{3} .
$$

Herein, $\overline{\mathbf{G}}_{i}$ are the base vectors defined by $\overline{\mathbf{G}}_{i}=\mathbf{G}_{k} \frac{A E \theta^{k}}{A E \zeta^{i}}$ with $\mathbf{G}_{k}=\frac{A E \mathbf{X}}{A E \theta^{k}}$, where $\mathbf{X}$ is the position vector. As known in the theory of shells, the base vectors describe the shell geometry [23]. As evident from (19) and (20), a set of six equations for each local subdomain $\Omega^{I}$ is obtained.

The next step is the discretization of the governing equations. In contrast to the standard displacement based formulation, here the displacement field, the strain components consisting of the three in-plane and the two transversal shear components, and the transversal normal stress component are approximated independently, by using the same in-plane interpolation functions. Linear polynomials are used for the distribution over the thickness, and the approximation in the in-plane directions is performed by means of the MLS functions. The displacement components are written in the directions of the Cartesian coordinates, $\mathbf{u}=u_{i} \mathbf{e}_{\mathrm{i}}$, while the strain and stress tensors are expressed in the parametric space as $\varepsilon=\varepsilon_{i j} \overline{\mathbf{G}}^{i} \otimes \overline{\mathbf{G}}^{j}$ and $\boldsymbol{\sigma}=\sigma^{i j} \overline{\mathbf{G}}_{i} \otimes \overline{\mathbf{G}}_{j}$. The undesired shear locking effect in the thin structural limit is suppressed by using the strain interpolation, and the transversal stress interpolation is applied for elimination of the thickness locking phenomena. 
As mentioned above, the modified MLS shape function with the interpolation property is used for the discretization. The Kronecker delta property is fulfilled with high accuracy; therefore, the penalty approach for imposing the displacement boundary conditions is not required. The interpolation condition is achieved by the modification of the weight function, which is now expressed in the following form:

$$
W_{J}\left(\xi^{\delta}\right)= \begin{cases}w_{S J} w_{R J}, & 0 \leq d_{J} \leq r_{J} \\ 0, & d_{J}>r_{J}\end{cases}
$$

As evident, the weight function is computed as a product of the two functions, $w_{S J}$ and $w_{R J}$, where $w_{S J}$ stands for the $4^{\text {th }}$-order spline function:

$$
w_{S J}=1-6\left(\frac{d_{J}}{r_{J}}\right)^{2}+8\left(\frac{d_{J}}{r_{J}}\right)^{3}-3\left(\frac{d_{J}}{r_{J}}\right)^{4},
$$

and $w_{R J}$ denotes the regularized weight function expressed as

$$
w_{R J}=\frac{\left(\left(\frac{d_{J}}{r_{J}}\right)^{4}+\varepsilon\right)^{-2}-(1+\varepsilon)^{-2}}{\varepsilon^{-2}-(1+\varepsilon)^{-2}} .
$$

In the above relations, $d_{J}=\left|\xi^{\gamma}-\xi_{J}^{\gamma}\right|$ is the distance between the node couple $J$ and the current sample point in the parametric space, while $r_{J}$ represents the support domain of the weight function. $\varepsilon$ is the regularization parameter, which should be very small and here it is assumed to be $\varepsilon=10^{-5}$.

Analogous to relation (10), the MLS nodal shape function is now expressed in the parametric plane as

$$
\phi_{J}\left(\xi^{\gamma}\right)=\sum_{i=1}^{m} p_{i}\left(\bar{\xi}^{\gamma}\right)\left[\mathbf{A}^{-1} \mathbf{B}\right]_{i J} .
$$

The matrices $\mathbf{A}$ and $\mathbf{B}$ are also derived in the in-plane parametric space. Using relation (25) and employing the linear polynomial interpolation in the $\zeta^{3}$ direction, the 3D shape function matrix $\boldsymbol{\Phi}_{J}^{\omega}\left(\xi^{i}\right)$ for the strain and the stress tensor components, as well as the matrix $\boldsymbol{\Phi}_{J}^{u}\left(\xi^{i}\right)$ for the displacement components, are derived. In the derivation procedure, which is described in detail in [12], the nodal strain values are computed by the well-known kinematic relations, and then expressed in terms of the nodal displacement components, in order to obtain a closed global system of equation with only the nodal displacements as unknown variables. After relatively complicated mathematical mani- 
pulations, the following final discretized form of the governing equations on the domain of influence level is obtained:

$$
\begin{aligned}
& \sum_{J=1}^{N_{I}}\left[\int_{L_{S}^{I}} \mathbf{N} \mathbf{T}^{\sigma} \tilde{\mathbf{C}} \boldsymbol{\Phi}_{J}^{\omega} \mathrm{d} \Gamma+\int_{\Gamma_{S u}^{I}} \mathbf{N} \mathbf{T}^{\sigma} \tilde{\mathbf{C}} \mathbf{\Phi}_{J}^{\omega} \mathrm{d} \Gamma\right] \sum_{K=1}^{\tilde{n}_{J}} \tilde{\mathbf{B}}_{K J} \hat{\mathbf{v}}_{K}= \\
& =-\int_{L_{S t}^{I}} \overline{\mathbf{t}} \mathrm{d} \Gamma-\int_{\Omega_{s}^{I}} \mathbf{b} \mathrm{d} \Omega, \\
& \sum_{J=1}^{N_{I}}\left[\int_{L_{S}^{I}} \xi^{3} \mathbf{N} \mathbf{T}^{\sigma} \tilde{\mathbf{C}} \boldsymbol{\Phi}_{J}^{\varepsilon} \mathrm{d} \Gamma+\int_{\Gamma_{S u}^{I}} \xi^{3} \mathbf{N} \mathbf{T}^{\sigma} \tilde{\mathbf{C}} \boldsymbol{\Phi}_{J}^{\omega} \mathrm{d} \Gamma-\int_{\Omega_{s}^{I}} \nabla \mathbf{d}^{T} \mathbf{T}^{\sigma} \tilde{\mathbf{C}} \boldsymbol{\Phi}_{J}^{\omega} \mathrm{d} \Omega\right] \\
& \sum_{K=1}^{\tilde{n}_{J}} \tilde{\mathbf{B}}_{K J} \hat{\mathbf{v}}_{K}=-\int_{L_{S t}^{I}} \xi^{3} \overline{\mathbf{t}} \mathrm{d} \Gamma-\int_{\Omega_{s}^{I}} \xi^{3} \mathbf{b} \mathrm{d} \Omega,
\end{aligned}
$$

where $\tilde{\mathbf{B}}_{K J}$ is the matrix containing derivatives of the 3-D shape functions; it is analogous to the standard strain-displacement matrix [24]. $\tilde{\mathbf{C}}$ is the material matrix, $\mathbf{T}^{\sigma}$ is the transformation matrix between the parametric space and the global Cartesian coordinates, and $\hat{\mathbf{v}}_{J}$ is the vector of the unknown displacement components in the directions of the global Cartesian coordinates at the upper and lower surface, respectively. $\mathbf{N}$ is the matrix containing the components of the outward unit normal vector $\mathbf{n}=n_{i} \mathbf{e}_{i}$ on the local sub-domain boundary, and $\nabla \mathbf{d}$ comprises the derivatives of $\xi^{3}$ with respect to the global Cartesian coordinates. $\tilde{n}_{J}$ denotes the number of nodes in the domain of influence of the node couple $J$. The closed global system of equations on the structural level is derived by using well-known numerical node-by-node assemblage procedures. The body forces are usually neglected in engineering computations, and therefore, all terms containing the body force vector $\mathbf{b}$ can be omitted.

\section{Cylindrical shell subjected to uniform line load}

As an example, a horizontal thin cylindrical shell subjected to the uniform line load of $q=1$ along the upper and lower generatrix is analyzed as shown in Fig. 8. The material data are the Young's modulus $E=210000$ and the Poisson's ratio $v=0.3$. The shell thickness is $h=0.9$, with the radius to thickness ratio of $R / h=100$. The length of the cylinder is $L=300$. Due to symmetry, only one octant of the shell is discretized by a uniform grid. 


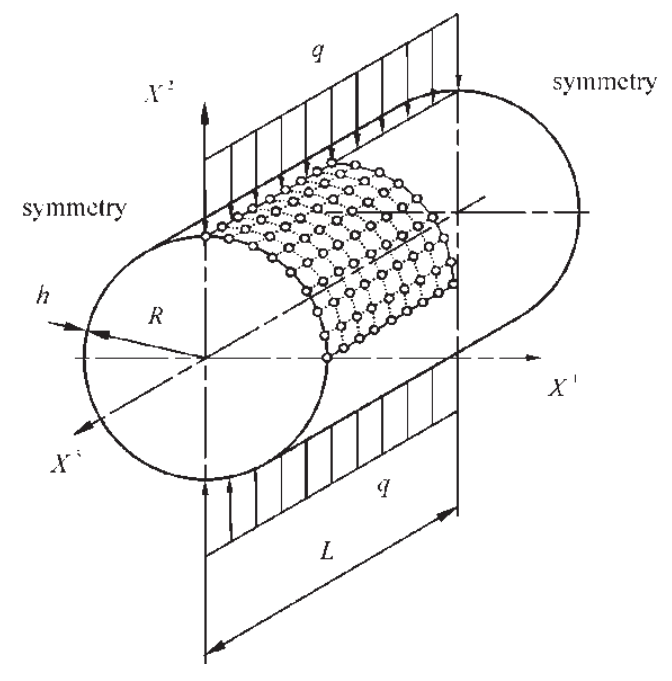

Fig. 8. Geometry and discretization of cylindrical shell

SI. 8. Geometrija i diskretizacija cilindrične ljuske

The computation is performed by the proposed mixed formulation, using the second- and third-order polynomial bases of the MLS function. The convergence of the vertical displacement at the shell middle surface under the line load, which is normalized by the analytical solution from [18], is presented in Fig. 9. The results are again compared with the values obtained by the full displacement approach taken from [24], as well as with the parabolic 3D finite elements from the MSC/NASTRAN program package [25]. As obvious from Fig. 9, the mixed meshless formulation is superior to other formulations displayed. The fifth-order basis function in the MLS interpolation has to be used in the full displacement approach in order to achieve the convergence, which significantly decreases numerical efficiency as mentioned before. Furthermore, it is again to note that the computation by the means of the third-order MLS basis function in the mixed approach yields the exact displacement values, even for the relatively coarse discretization. 


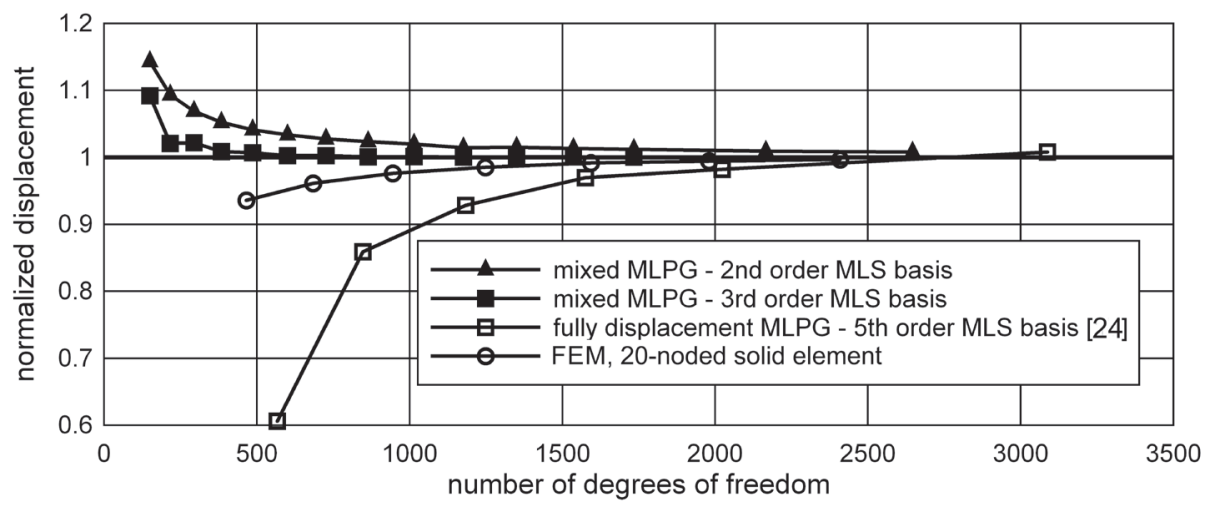

Fig. 9. Convergence of vertical displacement under line load for cylindrical shell

SI. 9. Konvergencija vertikalnog pomaka pod linijskim opterećenjem za cilindričnu ljusku

Furthermore, the sensitivity of the mixed approach to the shear locking effect has been tested by increasing the shell radius to thickness ratio, and the results are shown in Fig. 10. As evident, by using the second order MLS polynomial basis, the shear locking is again completely eliminated, even if very thin shells are considered.

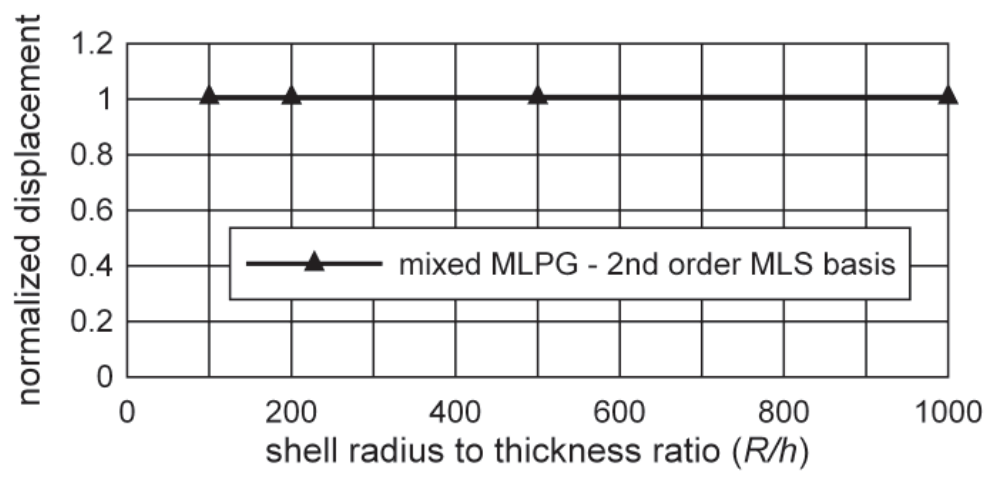

Fig. 10. Vertical displacement under line load vs. radius to thickness ratio for cylindrical shell SI. 10. Vertikalni pomak pod linijskim opterećenjem u odnosu na omjer polumjera i debljine stijenke za cilindričnu ljusku 


\section{MODELING MATERIAL DISCONTINUITY BY THE MEANS OF THE MESHLESS COLLOCATION METHOD}

The collocation mixed MLPG method is applied here for the modeling of material discontinuity. Instead of the previously described weak formulations, here the Dirac delta function is used as the test function in the local weak form. Each homogeneous region is discretized by using independent interpolations of both displacements and stress components. The MLS shape functions with interpolation property are used, which allows for a simple and direct imposition of the displacement and traction boundary conditions at the discretization nodes positioned on the global boundary, as well as the imposition of appropriate conditions at the nodes stationed at the material interface. No additional treatment or parameter determination at the material interface is needed. The final closed global system of discretized governing equations with the displacements as unknown variables is obtained through the kinematic and constitutive relations, similar as in the previous section. The details of this approach are given in [13].

A two-dimensional heterogeneous structure representing the global domain, which consists of two homogeneous parts $\Omega\left(\Omega=\Omega^{+} \cup \Omega^{-}\right)$bounded by the global outer boundary $\Gamma\left(\Gamma=\Gamma^{+} \cup \Gamma^{-}\right)$, is considered as shown in Fig. 11. The boundary $\Gamma_{s}$ represents the interface between two homogeneous isotropic materials, represented by domains $\Omega^{+}$and $\Omega^{-}$, with different linear elastic material properties, while $\mathbf{n}^{+}$and $\mathbf{n}^{-}$ denote unit outward normal vectors on their outer boundaries, $\Gamma^{+}$and $\Gamma^{-}$, and on the interface boundary $\Gamma_{s}$.

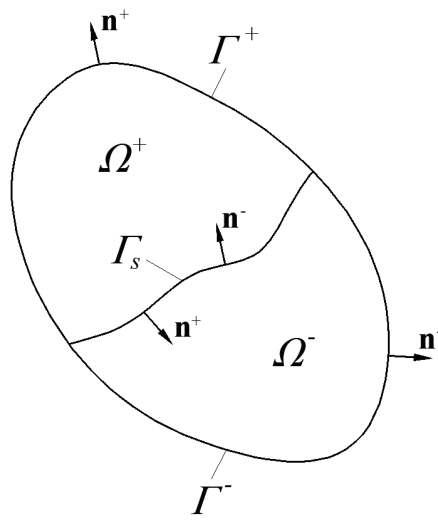

Fig. 11. Heterogeneous structure consisting of two homogeneous materials

SI. 11. Heterogena struktura koja se sastoji od dva homogena materijala 
The strong form of elasto-static governing equations can be defined for each homogeneous material separately, and accordingly the equilibrium equation for the homogeneous domain $\Omega^{+}$may be written as

$$
\sigma_{i j, x_{j}}^{+}+b_{i}^{+}=0, \quad \text { within } \Omega^{+},
$$

where $\sigma_{i j}^{+}$are the Cauchy stress tensor components, while $b_{i}^{+}$denotes body forces. On the outer boundaries $\Gamma^{+}$and $\Gamma^{-}$, the following displacement and traction boundary conditions have to be satisfied. Thus, for $\Gamma^{+}$, they are expressed as

$$
\begin{aligned}
& u_{i}^{+}=\bar{u}_{i}^{+}, \text {on } \Gamma_{u}^{+}, \\
& t_{i}^{+}=\sigma_{i j}^{+} n_{j}^{+}=\bar{t}_{i}^{+}, \text {on } \Gamma_{t}^{+} .
\end{aligned}
$$

Herein, $\Gamma_{u}^{+}$represents the part of the boundary $\Gamma^{+}$, where the displacement condition is prescribed, and $\Gamma_{t}^{+}$denotes the part where the traction boundary condition is imposed. The barred variables stand for the prescribed values of displacements and tractions. Analogous relations may be written for another homogeneous domain $\Omega^{-}$and its boundaries $\Gamma_{u}^{-}$and $\Gamma_{t}^{-}$. In order to obtain the solution for the entire heterogeneous structure, the interface conditions on the boundary $\Gamma_{s}$ should also be applied. These conditions are needed to impose the continuity of the displacement field along with the discontinuity (jump) in the displacement derivative field across the interface boundary $\Gamma_{s}$. This is fullfiled in a simple manner by enforcing the following equations at all nodes stationed on $\Gamma_{s}$

$$
\begin{aligned}
& u_{i}^{+}-u_{i}^{-}=0, \\
& \sigma_{i j}^{+} n_{j}^{+}+\sigma_{i j}^{-} n_{j}^{-}=0 .
\end{aligned}
$$

The discretization of the global computational domain $\Omega$ is performed by two different sets of nodes, $I=1,2, \ldots, N$ and $M=1,2, \ldots, P$, where $N$ and $P$ indicate the total number of nodes within homogeneous materials $\Omega^{+}$and $\Omega^{-}$, respectively. The interface boundary $\Gamma_{s}$ is discretized by overlapping nodes belonging to different homogeneous domains. The state fields at the discretization nodes associated with the material domain $\Omega^{+}$can only be influenced by the nodes from this domain. The same applies to the nodes belonging to the domain $\Omega^{-}$. 
According to the standard collocation approach, the strong form equilibrium equations at the discretization nodes are expressed as follows:

$$
\begin{gathered}
\sigma_{i j, x_{j}}^{+}\left(\mathbf{x}_{I}\right)+b_{i}^{+}\left(\mathbf{x}_{I}\right)=0, \quad \text { within } \Omega^{+}, \\
\sigma_{i j, x_{j}}^{-}\left(\mathbf{x}_{M}\right)+b_{i}^{-}\left(\mathbf{x}_{M}\right)=0, \quad \text { within } \Omega^{-} .
\end{gathered}
$$

The associated boundary and interface conditions can be written analogously. Like in the mixed approach proposed in [26], the displacement and stress components are chosen as the unknown field variables which are approximated separately within the homogeneous materials $\Omega^{+}$and $\Omega^{-}$, using the same field approximation functions. Hence, for the homogeneous material $\Omega^{+}$the approximated fields can be written as

$$
\begin{array}{ll}
u_{i}^{+(h)}\left(\mathbf{x}_{I}\right)=\sum_{J=1}^{N_{\Omega_{S}}} \phi_{J}\left(\mathbf{x}_{I}\right)\left(\hat{u}_{i}^{+}\right)_{J}, & \text { within } \Omega^{+}, \\
\sigma_{i j}^{+(h)}\left(\mathbf{x}_{I}\right)=\sum_{J=1}^{N_{\Omega_{S}}} \phi_{J}\left(\mathbf{x}_{I}\right)\left(\hat{\sigma}_{i j}^{+}\right)_{J}, & \text { within } \Omega^{+},
\end{array}
$$

where $\phi_{J}$ represents the nodal value of the two-dimensional shape function for node $J$, $N_{\Omega_{S}}$ stands for the number of nodes within the approximation domain, while $\left(\hat{u}_{i}^{+}\right)_{J}$ and $\left(\hat{\sigma}_{i j}^{+}\right)_{J}$ denote the nodal values of displacement and stress components. The displacement and stress components over the material domain $\Omega^{-}$are analogously approximated. The MLS approximation scheme with the interpolation property is used, which has already been described in the previous section.

According to the mixed MLPG paradigm, the equilibrium collocation equations (33) and (34) are first discretized by the stress approximations leading to the system of equations with the stress nodal variables, as presented in [13]. Then, in order to obtain the closed system of the governing equations with the displacement components as unknown nodal variables, the nodal stress components are expressed by means of the constitutive relations and the kinematic equations. Accordingly, for one homogeneous region $\Omega^{+}$the following matrix relation may be derived:

$$
\hat{\boldsymbol{\sigma}}_{J}^{+}=\mathbf{D}^{+} \sum_{L=1}^{N_{\Omega_{s}}} \mathbf{B}_{J L}^{+} \hat{\mathbf{u}}_{L}^{+}, \quad \text { within } \Omega^{+},
$$

where $\mathbf{D}^{+}$denotes the elasticity matrix, and $\mathbf{B}_{J L}^{+}$is the matrix composed of first-order spatial derivatives of the nodal shape functions for the $J^{\text {th }}$ node influencing the approximation at node $L . \hat{\mathbf{u}}_{L}^{+}$stands for the nodal values of displacements. Analogous relations are derived for another homogeneous region $\Omega^{-}$. 
Finally, the discretized system of equations can be written for the nodes of each homogeneous domain $\Omega^{+}$and $\Omega^{-}$as

$$
\begin{aligned}
& \sum_{J=1}^{N_{\Omega_{S}}} \mathbf{K}_{I J}^{+} \hat{\mathbf{u}}_{J}^{+}=\mathbf{R}_{I}^{+}, \quad I=1,2, \ldots, N, \quad \text { within } \Omega^{+}, \\
& \sum_{J=1}^{N_{\Omega_{s}}} \mathbf{K}_{M J}^{-} \hat{\mathbf{u}}_{J}^{-}=\mathbf{R}_{M}^{-}, \quad M=1,2, \ldots, P, \quad \text { within } \Omega^{-},
\end{aligned}
$$

where $\mathbf{K}_{I J}^{+}$and $\mathbf{K}_{M J}^{-}$are the nodal stiffness matrices, while $\mathbf{R}_{I}^{+}$and $\mathbf{R}_{M}^{-}$stand for the nodal force vectors. The discretized displacement boundary conditions can be written simply as

$$
\begin{aligned}
& \overline{\mathbf{u}}_{I}^{+}=\sum_{L=1}^{N_{\Omega_{s}}} \phi_{L} \hat{\mathbf{u}}_{L}^{+}, \quad \text { on } \Gamma_{u}^{+}, \\
& \overline{\mathbf{u}}_{M}^{-}=\sum_{L=1}^{N_{\Omega_{s}}} \phi_{L} \hat{\mathbf{u}}_{L}^{-}, \quad \text { on } \Gamma_{u}^{-},
\end{aligned}
$$

and the discretized traction boundary conditions are computed as

$$
\begin{aligned}
& \overline{\mathbf{t}}_{I}^{+}=\mathbf{N}_{I}^{+} \mathbf{D}^{+} \sum_{L=1}^{N_{\Omega_{S}}} \mathbf{B}_{I L}^{+} \hat{\mathbf{u}}_{L}^{+}, \quad \text { on } \Gamma_{t}^{+}, \\
& \overline{\mathbf{t}}_{M}^{-}=\mathbf{N}_{M}^{-} \mathbf{D}^{-} \sum_{L=1}^{N_{\Omega_{S}}} \mathbf{B}_{M L}^{-} \hat{\mathbf{u}}_{L}^{-}, \quad \text { on } \Gamma_{t}^{-},
\end{aligned}
$$

where $\mathbf{N}_{I}^{+}$and $\mathbf{N}_{M}^{-}$denote the matrices containing outward unit normal vector components to $\Gamma_{t}^{+}$or $\Gamma_{t}^{-}$. The following discretized interface boundary conditions may be written as

$$
\begin{gathered}
\sum_{L=1}^{N_{\Omega_{s}}} \phi_{L} \hat{\mathbf{u}}_{L}^{+}=\sum_{L=1}^{N_{\Omega_{s}}} \phi_{L} \hat{\mathbf{u}}_{L}^{-}, \quad \text { on } \Gamma_{s}, \\
\mathbf{N}_{I}^{+} \mathbf{D}^{+} \sum_{L=1}^{N_{\Omega_{s}}} \mathbf{B}_{I L}^{+} \hat{\mathbf{u}}_{L}^{+}=\mathbf{N}_{M}^{-} \mathbf{D}^{-} \sum_{L=1}^{N_{\Omega_{s}}} \mathbf{B}_{M L}^{-} \hat{\mathbf{u}}_{L}^{-}, \quad \text { on } \Gamma_{s} .
\end{gathered}
$$

The global system of equations for the entire heterogeneous structure is obtained by looping through all the nodes belonging to the material sub-domains $\Omega^{+}$and $\Omega^{-}$using the standard well-known procedure.

\section{Plate with circular inclusion}

As an example, a rectangular square plate with dimensions $2 L \times 2 L$ and the circular inclusion with radius $R=1$ subjected to the unit horizontal traction $t^{0}$ is considered as depicted in Fig. 12. 


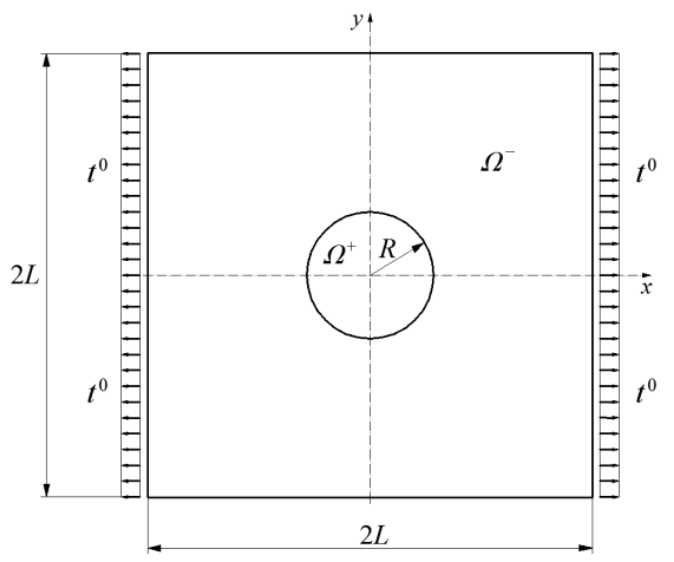

Fig. 12. Plate with circular inclusion subjected to uniform traction

SI. 12. Ploča s okruglim umetkom podvrgnuta jednolikom istezanju

Due to the symmetry, only one quarter of the plate consisting of the two sub-domains $\Omega^{-}$and $\Omega^{+}$has been discretized as shown in Fig. 13. As obvious, the symmetry boundary conditions are used along the left and bottom edges, while the tractions $\bar{t}_{x}^{\mathrm{a}}$ and $\overline{t_{y}^{\mathrm{a}}}$, taken from the analytical solution [27], are prescribed on all outer edges. The material properties of the plate are $E^{+}=1000, v^{+}=0.25$, while the values of $E^{-}=10000$ and $v^{-}=0.3$ have been chosen for the inclusion.

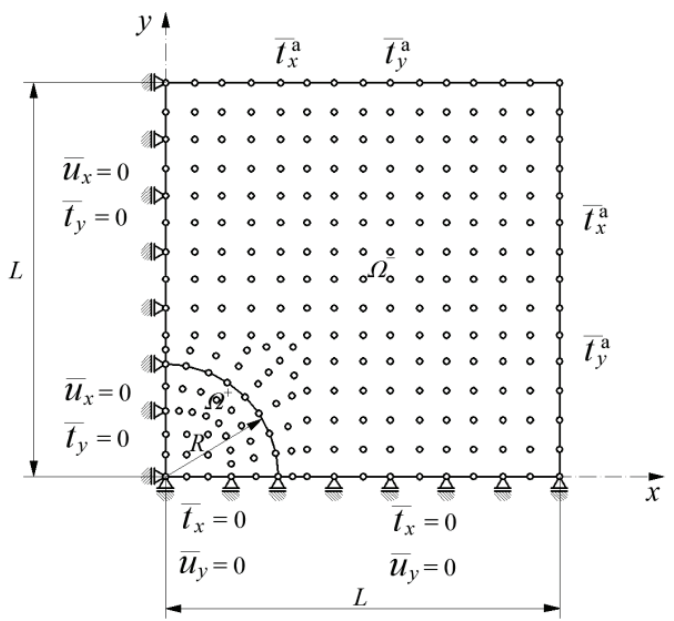

Fig. 13. Computational model of plate with circular inclusion with boundary conditions

SI. 13. Računalni model ploče s okruglim umetkom i rubnim uvjetima 
The computation is performed by using the MLS interpolation functions employing the second- and third-order basis (IMLS2, IMLS3). The accuracy of the numerical solutions is again compared to the analytical solutions [27]. The distributions of the strain components $\varepsilon_{x}$ and the stress component $\sigma_{x}$ for $x=0$ are presented in Figs 14 and 15. The results obtained by the proposed mixed formulation by using the second- (IMLS2$\mathrm{M}$ ) and third-order (IMLS3-M) functions are also compared with the solutions obtained by the full displacement (primal) approach [5], using the same order basis (IMLS2-P and IMLS3-P). The superiority of the proposed mixed approach is evident.

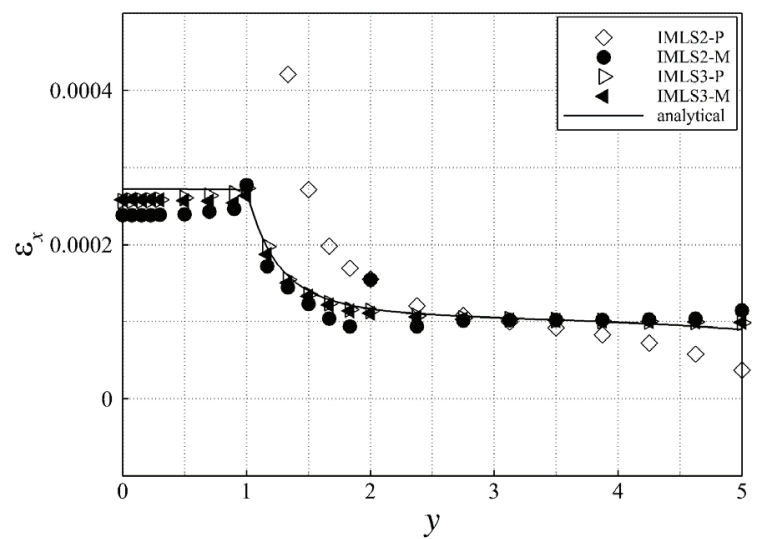

Fig. 14. Plate with circular inclusion - distribution of strain $\varepsilon_{x}$ za $x=0$

SI. 14. Ploča s okruglim umetkom - raspodjela deformacije $\varepsilon_{x}$ za $x=0$

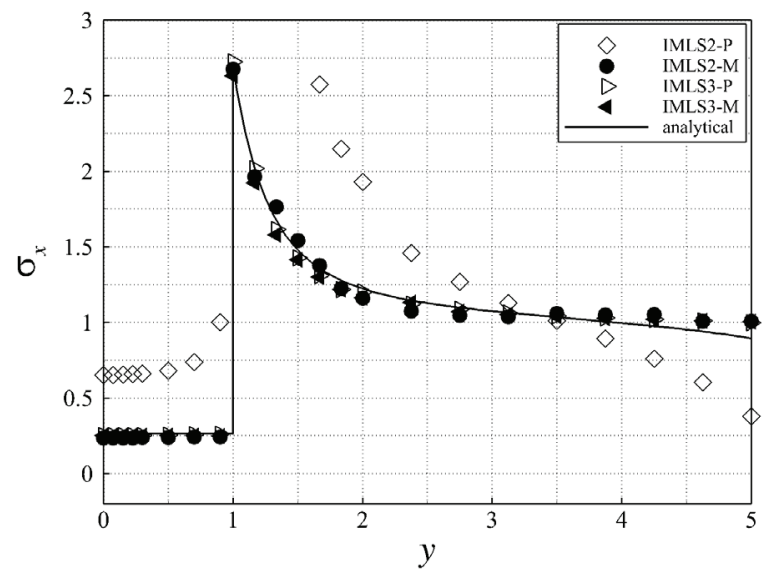

Fig. 15. Plate with circular inclusion - distribution of stress $\sigma_{x}$ for $x=0$

SI. 15. Ploča s okruglim umetkom - raspodjela naprezanja $\sigma_{x}$ za $x=0$ 
Finally, the numerical efficiency of the proposed collocation formulation has been tested by investigating the convergence rate and computational time, and the results have been compared to those obtained by the FEM. The global stress convergence rates are portrayed in Fig. 16. Herein, the results obtained by the first-order triangular (CPS3), the first-order quadrilateral (CPS4), the second-order triangular (CPS6) and the quadrilateral (CPS8) elements from the ABAQUS [28] are compared to those computed by the proposed mixed MLPG collocation utilizing the second- and third-order MLS functions (IMLS2 and IMLS3, respectively). The available analytical solutions from [27] are used as the referent values. The discretized $L_{2}$ norm expressed as

$$
e_{\sigma}=\sum_{k=1}^{N} \sqrt{\frac{\left(\sigma_{x}^{\mathrm{NUM}}-\sigma_{x}^{\mathrm{ANAL}}\right)_{k}^{2}+\left(\sigma_{y}^{\mathrm{NUM}}-\sigma_{y}^{\mathrm{ANAL}}\right)_{k}^{2}+\left(\tau_{x y}^{\mathrm{NUM}}-\tau_{x y}^{\mathrm{ANAL}}\right)_{k}^{2}}{\left(\sigma_{x}^{\mathrm{ANAL}}\right)_{k}^{2}+\left(\sigma_{y}^{\mathrm{ANAL}}\right)_{k}^{2}+\left(\tau_{x y}^{\mathrm{ANAL}}\right)_{k}^{2}}},
$$

is used as error indicator computed at all nodes of the numerical models considered. Here, $\sigma_{x}$ and $\sigma_{y}$ are normal stress components, while $\tau_{x y}$ represents the shear stress. The superscript NUM denotes numerical solutions, obtained either by FEM or by MLPG approach. The superscript ANAL stands for the analytical solutions. $\mathrm{N}$ denotes the number of nodes.

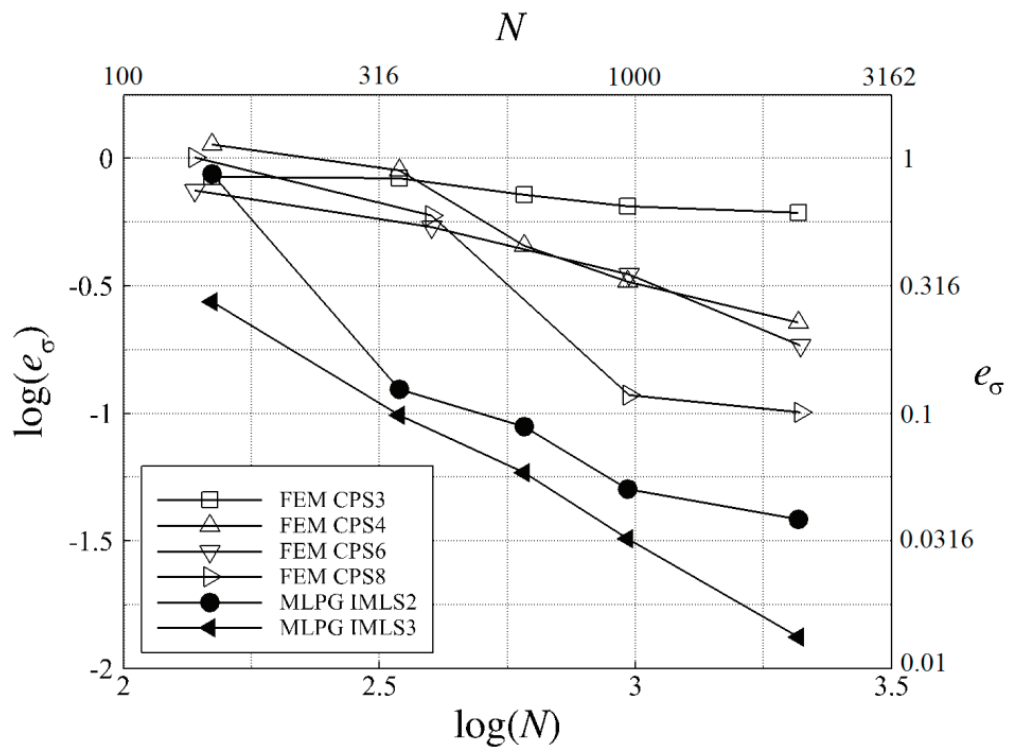

Fig. 16. Plate with circular inclusion - comparison of numerical stress accuracy with FEM

SI. 16. Ploča s okruglim umetkom - usporedba točnosti naprezanja s FEM (metodom konačnih elemenata) 
It can be seen from Fig. 16 that the meshless approach is superior to the above-mentioned finite element formulations with respect to the convergence rates and the numerical accuracy. The computational time for the meshless method is shorter than for the FEM, especially for the model with fewer nodes, indicating that the presented approach could be a potentially interesting alternative to the FEM in solving similar problems. It is important to emphasize that a further careful optimization of the developed meshless code is necessary in order to make a more trustworthy assessment about the numerical efficiency of the present approach.

\section{CONCLUSIONS}

Three different formulations of the meshless local Petrov-Galerkin approach are presented. The three-dimensional full displacement formulation is derived and applied for the solution of the elasto-static problem. It is evident that this approach is highly efficient in solving strongly singular problems, such as the Boussinesq problem. The presented method achieves significantly higher accuracy with only one-third as many nodes as compared to the finite element method. An efficient mixed meshless formulation based on the local Petrov-Galerkin approach for the analysis of plate and shell structures has been displayed. Here, the superiority of the mixed formulation in comparison to the standard full displacement approach is demonstrated. Using the strain and stress approximations, the undesired thickness and shear locking phenomena, which are a well-known drawback of the shell finite element formulations, are efficiently eliminated. The results also show that the accuracy and convergence of the mixed meshless formulation are better than that of the finite element used. The third meshless formulation is based on the mixed collocation approach. Therein, the deformation responses of heterogeneous structures are modeled. The discontinuities in the strain and stress fields due to the material heterogeneity are captured accurately. Again, the numerical efficiency of the proposed method is estimated by comparison to the FEM with respect to accuracy, convergence rates and computational time. The present method yields convergence rates, which are larger or comparable to those obtained by the FEM, while at the same time, it is more accurate for the same number of degrees of freedom. On the other hand, the FEM method is still faster for equal number of the degrees of freedom. Nevertheless, as the collocation method needs fewer nodes to achieve the same level of global accuracy as the FEM, the computational time required for solving an engineering problem might be shorter or comparable to that of the FEM.

It is to note that the construction of meshless shape functions is rather complex in nature in comparison to the polynomial functions within the mesh-based methods. 
Thus, the number of integration points required for an exact calculation of the integrals in the meshless methods based on the weak forms may be higher than in the FEM, because the shape functions are often not of polynomial character.

\section{References}

[1] N. Perrone, R. Kao, A general finite difference method for arbitrary meshes, Computers \& Structures, 5(1) (1975) 45-57.

[2] B. Šarler, J. Perko, C.-S. Chen, Radial basis function collocation method solution of natural convection in porous media, International Journal of Numerical Methods for Heat \& Fluid Flow, 14(2) (2004) 187-212.

[3] H.-Y. Hu, Z.-C. Li, A. H.-D. Cheng, Radial basis collocation methods for elliptic boundary value problems, Computers \& Mathematics with Applications, 50(1-2) (2005) 289-320.

[4] T. Belytschko, Y. Y. Lu, L. Gu, Element free Galerkin methods, International Journal for Numerical Methods in Engineering, 37(2) (1994) 229-256.

[5] S. N. Atluri, T. Zhu, A new Meshless Local Petrov-Galerkin (MLPG) approach in computational mechanics, Computational Mechanics, 22(2) (1998) 117-127.

[6] W. K. Liu, S. Jun, Y. F. Zhang, Reproducing kernel particle methods, International Journal for Numerical Methods in Fluids, 20(8-9) (1995) 1081-1106.

[7] C. A. Duarte, J. T. Oden, H-p Clouds - An h-p Meshless Method, Numerical Methods for Partial Differential Equations, 12(6) (1996) 673-705.

[8] S. N. Atluri, T.-L. Zhu, The meshless local Petrov-Galerkin (MLPG) approach for solving problems in elasto-statics, Computational Mechanics, 25(2-3) (2000) 169-179.

[9] G. R. Liu, Y. T. Gu, A meshfree method: meshfree weak-strong (MWS) form method for 2-D solids, Computational Mechanics, 33(1) (2203) 2-14.

[10] G. R. Liu, Y. L. Wu, H. Ding, Meshfree weak-strong (MWS) form method and its application to incompressible flow problems, International Journal for Numerical Methods in Fluids, 46(10) (2004) 1025-1047.

[11] Q. Li, S. Shen, Z. D. Han, S. N. Atluri, Application of Meshless Local Petrov-Galerkin (MLPG) to Problems with Singularities, and Material Discontinuities, in 3-D Elasticity, CMES: Computer Modeling in Engineering \& Sciences, 4(5) (2003) 571-585.

[12] J. Sorić, T. Jarak, Mixed meshless formulation for analysis of shell-like structures, Computer Methods in Applied Mechanics and Engineering, 199 (17-20) (2010) 1153-1164.

[13] B. Jalušić, J. Sorić, T. Jarak, Mixed meshless local Petrov-Galerkin collocation method for modeling of material discontinuity, Computational Mechanics, 59 (1) (2017) 1-19.

[14] P. Lancaster, K. Salkauskas, Curve and surface fitting: an introduction. Academic Press Ltd, London (1986).

[15] S. N. Atluri, H.-G. Kim, J. Y. Cho, A critical assessment of the truly meshless local PetrovGalerkin (MLPG) and Local Boundary Integral Equation (LBIE) methods, Computational Mechanics, 24(5) (1999) 348-372. 
[16] P. Breikopf, A. Rassineux, G. Touzot, P. Villon, Explicit form and efficient computation of MLS shape functions and their derivatives, International Journal for Numerical Methods in Engineering, 48(3) (2000) 451-466.

[17] S. N. Atluri, S. Shen, The meshless local Petrov-Galerkin (MLPG) method, Tech Science Press, Encino, USA (2002).

[18] S. Timoshenko, J. N. Goodier, Theory of elasticity, McGraw-Hill Book Company, New York, USA (1951).

[19] R. Hauptmann, K. Schweizerhof, A systematic development of solid-shell element formulations for linear and non-linear analyses employing only displacement degrees of freedom, International Journal for Numerical Methods in Engineering, 42(1) (1998) 49-69.

[20] S. Klinkel, F. Gruttmann, W. Wagner, A robust non-linear solid shell element based on a mixed variational formulation, Computer Methods in Applied Mechanics and Engineering, 195(1-3) (2006) 179-201.

[21] T. Most, C. Bucher, A Moving Least Squares weighting function for the Element-free Galerkin Method which almost fulfills essential boundary conditions, Structural Engineering and Mechanics 21(3) (2005) 315-332.

[22] T. Most, A natural neighbour-based moving least-squares approach for the element-free Galerkin method, International Journal for Numerical Methods in Engineering,71(2) (2007) 224-252.

[23] Y. Basar, W.B. Krätzig, Theory of Shell Structures, VDI Verlag (2001).

[24] T. Jarak, J. Sorić, J. Hoster, Analysis of shell deformation responses by the Meshless Local Petrov-Galerkin (MLPG) approach, CMES: Computer Modeling in Engineering \& Sciences, 18(3) (2007) 235-246.

[25] MSC.Software Corporation, MSC.Nastran 2005 Quick Reference Guide, MSC.Software Corporation, USA (2005).

[26] S. N. Atluri, H. T. Liu, Z. D., Meshless local Petrov-Galerkin (MLPG) mixed collocation method for elasticity problems, CMES: Computer Modeling in Engineering \& Sciences 14(3) (2006) 141-152.

[27] M. Kachanov, B. Shafiro, I. Tsukrov, Handbook of Elasticity Solutions, Springer Science+Business Media, Dordrecht (2003).

[28] ABAQUS/Standard, Dassault Systemes, Providence, Rhode Island, USA (2014). 
J. Sorić, B. Jalušić, T. Jarak: Meshless approach as an alternative to finite element method in ...

\title{
BEZMREŽNI POSTUPAK KAO ALTERNATIVA METODI KONAČNIH ELEMENATA PRI NUMERIČKOM MODELIRANJU U MEHANICI ČVRSTIH TIJELA
}

\section{Sažetak}

Bezmrežni postupak omogućuje diskretizaciju računalnog modela samo s čvorovima koji ne trebaju biti povezani s konačnim elementima. U ovom članku prikazuje se lokalna Petrov-Galerkinova formulacija koja u potpunosti spada u bezmrežne postupke jer ne zahtijeva niti jednu vrstu mreže ili tzv. popratnih ćelija, kako za interpolaciju tako i za integraciju. Prikazane su puna formulacija pomaka i mješovita formulacija. Postupak punog pomaka se primjenjuje za rješavanje trodimenzijskog elasto-statičkog problema, dok se mješovita formulacija koristi za modeliranje deformiranja ljuskastih konstrukcija. Modeliranje materijalnog diskontinuiteta se provodi mješovitim bezmrežnim lokalnim Petrov-Galerkinovim postupkom koji uključuje kolokacijsku metodu. U numeričkim primjerima, učinkovitost $\mathrm{i}$ točnost svih prikazanih metoda je testirana i uspoređena s formulacijama metode konačnih elemenata. Pokazano je da se bezmrežni postupci mogu smatrati alternativom za dobro poznatu metodu konačnih elemenata.

Ključne riječi: Bezmrežna metoda; lokalna Petrov-Galerkinova formulacija; mješoviti bezmrežni postupak; kolokacijski bezmrežni postupak.

\author{
Jurica Sorić", Boris Jalušić, Tomislav Jarak \\ University of Zagreb \\ Faculty of Mechanical Engineering and Naval Architecture \\ Ivana Lučića 5, 10000 Zagreb, \\ E-mail: jurica.soric@fsb.hr; boris.jalusic@fsb.hr; tomislav.jarak@fsb.hr \\ * član suradnik HAZU
}

